\title{
Huangdi Anxiao Attenuated High Glucose-Induced PC12 Cells Neurotoxicity via Inhibiting Apoptosis Pathway of Endoplasmic Reticulum Stress
}

\section{Ting Ye}

School of Integrated Chinese and Western Medicine, Anhui University of Chinese Medicine, Hefei 230012, China.

\section{Wei-ting Xuan}

Department of Neurosurgery(Rehabilitation), Anhui Hospital of Integrated Chinese and Western Medicine, Hefei 230031, China.

\section{Peng Zhou}

School of Integrated Chinese and Western Medicine, Anhui University of Chinese Medicine, Hefei 230012, China.

\section{Nan Shao}

School of Integrated Chinese and Western Medicine, Anhui University of Chinese Medicine, Hefei 230012, China.

\section{Hang Song}

School of Integrated Chinese and Western Medicine, Anhui University of Chinese Medicine, Hefei 230012, China.

\section{Yan Wang}

School of Integrated Chinese and Western Medicine, Anhui University of Chinese Medicine, Hefei 230012, China.

\section{Guan-hua Hu}

School of Integrated Chinese and Western Medicine, Anhui University of Chinese Medicine, Hefei 230012, China.

\section{Ting-ting Wang}

School of Integrated Chinese and Western Medicine, Anhui University of Chinese Medicine, Hefei 230012, China.

\section{Guang-yun Wang ( $\nabla$ wgyhefei@163.com )}

School of Integrated Chinese and Western Medicine, Anhui University of Chinese Medicine, Hefei 230012, China.

\section{Zhao-hui Fang}

Department of Endocrinology, First Affiliated Hospital of Anhui University of Chinese Medicine, Hefei 230031, China.

\section{Biao Cai}


School of Integrated Chinese and Western Medicine, Anhui University of Chinese Medicine, Hefei 230012, China.

\section{Research Article}

Keywords: Huangdi Anxiao, Diabetic cognitive dysfunction, Neuroprotection, Apoptosis pathway of endoplasmic reticulum stress

Posted Date: December 29th, 2021

DOI: https://doi.org/10.21203/rs.3.rs-1169332/v1

License: (a) This work is licensed under a Creative Commons Attribution 4.0 International License. Read Full License 


\section{Abstract \\ Background}

Huangdi Anxiao (HDAX) is mainly used to treat diabetes and its complications for many years and has a remarkable curative effect. However, the improvement effect of HDAX in the diabetic cognitive dysfunction (DCD) model and the related mechanism is not clear. This study was aimed to explore the neuroprotective effects of HDAX and its possible mechanisms in DCD.

\section{Methods}

A DCD cell model was established by high glucose-induced PC12 cells, and the effect of HDAX on the cell viability was examined by MTT. Additionally, the expression of relevant genes and proteins in the apoptosis pathway of endoplasmic reticulum (ER) stress was detected.

\section{Results}

The results showed that HDAX increased cell viability, reduced GRP78, CHOP, Bax, procaspase-12, procaspase-9, procaspase-3 mRNA levels and GRP78, CHOP, Bax, Caspase-12, Caspase-9, Caspase-3 protein expressions, and decreased Bcl-2 mRNA level and protein expression.

\section{Conclusions}

These results suggested that HDAX had neuroprotective effects in the DCD cell model, which may be associated with the inhibition of the apoptosis pathway of ER stress.

\section{Background}

Diabetic cognitive dysfunction (DCD) is a neuropathy caused by sustained hyperglycemia, which is one of the serious complications of diabetes. It is mainly manifested as the decrease of learning and memory ability, accompanied by pathological changes in brain structure and neurological function, which seriously affects the quality of life [1]. Studies have shown that people with diabetes are at least twice as likely to have severe impairment of cognitive function, type 2 diabetes mellitus (T2DM) is a risk for Alzheimer's disease (AD) [2,3]. Although a growing number of researchers have studied over the past few decades, the pathogenesis of $D C D$ remains unclear.

Glucose is the main source of energy, which mammalian brain and its essential function for the normal brain. Recent studies have shown that high glucose is the most fundamental cause of DCD, high glucose environment can lead to increased apoptosis of nerve cells, decrease the ability of learning and memory, and eventually lead to the occurrence of DCD [4]. Besides, chronic hyperglycemia can promote the 
deposition of Amyloid beta-peptide (AB), increase the sensitivity of nerve cells, and thus generate $A \beta$ of neurotoxicity to cerebral microvascular endothelial cells [5]. Some experimental studies showed that high glucose-induced brain insulin resistance leads to changes similar to AD [6]. The exact mechanism of the nerve cell damage caused by high glucose is unclear, but studies have shown that glucose toxicity causes metabolic abnormalities in the following pathways: Endoplasmic reticulum (ER) stress, oxidative stress, inflammatory response, insulin resistance, etc. [7-9]. The apoptosis pathway of ER stress is hot in recent years.

The apoptosis pathway of ER stress has been increasingly studied in the occurrence and development of various diabetic complications [10]. ER stress response can be triggered by different factors, such as high glucose environment, inflammatory cytokines, the disorder of calcium balance, oxidative damage, etc. [11], through unfolded protein response (UPR) protect and restore cell function. However, when the injury cannot be recovered in time, UPR can further regulate the downstream apoptotic signaling molecules such as $\mathrm{C} / \mathrm{EBP}$ homologous protein (CHOP), Cysteinyl aspartate specific proteinase (Caspase), and B-cell lymphoma-2 (Bcl-2) family to induce apoptosis [12]. In recent years, to find an effective treatment for $D C D$, researchers have begun to try to alleviate the disease by regulating the apoptosis pathway of ER stress. Therefore, the development of appropriate drugs has become a hot spot and basic research in a clinic of DCD.

Huangdi Anxiao (HDAX) is a hospital formula from Anhui Provincial Hospital of Chinese Medicine. It is mainly used to treat diabetes and its complications for many years and has a remarkable curative effect $[13,14]$. However, the improvement effect of HDAX in the DCD model and the related mechanism is not clear. We speculate that HDAX may be effective in the treatment of DCD by inhibiting the apoptosis pathway of ER stress. To elucidate the mechanism of HDAX therapy of DCD, we used high glucose to build DCD vitro model in PC12 cells, to explore the ability of HDAX in neuroprotective effects and related proteins and gens.

\section{Materials And Methods}

\section{Materials}

HDAX were mainly composed of Coptidis Rhizoma, Radix Rehmanniae, Radix Puerariae, Radix Ophiopogonis, Eriobotryae Folium, and Radix Notoginseng, which were purchased from Anhui Provincial Hospital of Chinese Medicine. Notoginsenoside R1, ginsenoside Rg1, puerarin, acteoside, berberine, coptisine, and palmatine hydrochloride were purchased from Shanghai yuanye Bio-Technology Co., Ltd (Shanghai, China). 4-phenylbutyric acid (4-PBA) was purchased from Sigma-Aldrich (St. Louis, MO, USA). The primary antibody of GRP78, CHOP was purchased from Affinity Bioscience (1:1300, USA); Caspase12, Caspase-9, Caspase-3 were obtained from Bioss (1:1000, Beijing, China); Bax, Bcl-2 was provided by Bioworld (1:1000, Nanjing, China).

\section{Preparation of HDAX}


HDAX solution was prepared by boiling these six components Coptidis Rhizoma (6 g), Radix Rehmanniae (10 g), Radix Puerariae (10 g), Radix Ophiopogonis (8g), Eriobotryae Folium (12 g), and Radix

Notoginseng $(5 \mathrm{~g})$ in water. Adding and refluxing 10 -fold water for $1.5 \mathrm{~h}$, then adding 8 -fold water and repeated before for $1.0 \mathrm{~h}$. Then, collecting the solution and concentrating to $10 \mathrm{mg} / \mathrm{mL}$, and stored at $4^{\circ} \mathrm{C}$.

\section{Ultra-performance liquid chromatography (UPLC) analysis of HDAX}

Puerarin, acteoside, coptisine, palmatine hydrochloride, berberine, notoginsenoside R1, and ginsenoside Rg1 in HDAX were measured by UPLC. An Acquity BEH C18 analytical column coupled with a column filter at $30^{\circ} \mathrm{C}$. Gradient elution with $0.05 \%(\mathrm{v} / \mathrm{v})$ phosphoric acid in distilled water $(\mathrm{A})$ and acetonitrile $(\mathrm{B})$ : $3 \%-15 \%$ B for 0-6 min, $15 \%-27 \%$ B for $6-7$ min, $27 \%-27 \%$ B for $7-13 \mathrm{~min}, 27 \%-70 \%$ B for $13-15 \mathrm{~min}, 70 \%-3 \%$ $B$ for $15-16 \mathrm{~min}$. The flow rate is $0.2 \mathrm{~mL} / \mathrm{min}$ and injection volumes is $1 \mu \mathrm{L}$. Finally monitored at $203 \mathrm{~nm}$ and $260 \mathrm{~nm}$.

\section{Preparation of HDAX containing serum}

Twenty rats were divided into two groups randomly: Control group, HDAX group, 10 rats in one group. Referring to the method of the previous experiment(Cai et al., 2018), HDAX was prepared into the solution at a dose of $10.5 \mathrm{~g} / \mathrm{kg}$ ( 7 times of the clinical equivalent dose), the drug was given by gavage of 10 $\mathrm{mL} / \mathrm{kg}$ for $5 \mathrm{~d}$. The control group was given an equal volume of normal saline. After the last administration, each group was collected blood samples under the abdominal aorta under aseptic conditions, centrifugation for $15 \mathrm{~min}$ at $3000 \mathrm{r} / \mathrm{min}$, serum samples were collected, inactivated for $56^{\circ} \mathrm{C}$ for $30 \mathrm{~min}$, and stored at $-20^{\circ} \mathrm{C}$ for later use.

\section{Cell culture and treatments}

PC12 cells were cultured in Dulbecco modified Eagle medium (DMEM, Thermo Fisher Scientific, Inc., Waltham, USA) in an incubator containing $5 \% \mathrm{CO}_{2}$ at $37^{\circ} \mathrm{C}$. They were digested by $0.25 \%$ pancreatin for passage when the cells reached the confluence rate of above $80 \%$.

Based on the 3-(4,5-dimethylthiazol-2-yl)-2,5-diphenyltetrazolium (MTT) experiment, the PC12 cells were assigned to the following treatment groups: Control, Model, 15\% HDAX containing serum group (HDAX), 4-PBA inhibitor group (4-PBA), and 15\% HDAX containing serum+4-PBA inhibitor group (HDAX+4-PBA). The model group was incubated with $100 \mathrm{mM}$ glucose for $48 \mathrm{~h}$ to establish the DCD cell model. HDAX+4PBA group were incubated with 15\% HDAX containing serum and $5 \mu \mathrm{M}$ 4-PBA inhibitor, HDAX, and 4-PBA groups were given $15 \%$ HDAX containing serum and $5 \mu \mathrm{M}$ 4-PBA inhibitor, respectively. establishing the DCD cell model after $24 \mathrm{~h}$.

\section{Cell viability}

Add MTT solution ( $20 \mu \mathrm{L}, 5 \mathrm{mg} / \mathrm{mL}$ ) to each hole and incubated, then solubilize the precipitated dye with DMSO. After dissolved for 10-15 min, measured the absorbance at $490 \mathrm{~nm}$ with a microplate reader $(318 \mathrm{C}+$, Shanghai, China). 


\section{The observation of inverted microscope}

The cells were seeded onto a six-well plate at a density of $1 \times 10^{6}$ cell $/ \mathrm{m}$. The cells were treated with glucose $(50,75,100,125,150 \mathrm{mM})$ for $48 \mathrm{~h}$. When the cell growing time and density meet the requirement, we selected the clear field of views to observe the morphology and structure of the cells by inverted microscope.

\section{Hoechst 33342 staining}

PC12 cells in the logarithmic growth stage were treated according to different groups. After fixation with $4 \%$ paraformaldehyde for $10 \mathrm{~min}, 1 \mathrm{~mL}$ Hoechst 33342 dye diluent was added to each hole and was treated at $37^{\circ} \mathrm{C}$ incubator for 20-30 min, then PBS washed for 2-3 times about 1-2 min. Observing and photographing by fluorescence microscopy (Olympus IX71).

\section{Quantitative real-time PCR (RT-qPCR)}

Total mRNA of cells was extracted by Trizol reagent (Ambion, USA). The complementary cDNA was synthesized with RevertAid First Strand cDNA Synthesis Kit (Thermo Scientific, Massachusetts, USA). According to SYBR (TOYOBO, Japan), mRNA was detected by 7500 real-time PCR (Applied Biosystems, Foster City, CA). All target gene primers were designed with the comparative $\mathrm{Ct}\left(2^{-\Delta \Delta C t}\right)$ (cycle threshold) method which is listed below. 
Table 1

\begin{tabular}{|c|c|c|}
\hline \multicolumn{2}{|l|}{ Gene } & \multirow{2}{*}{$\begin{array}{l}\text { Sequences }\left(5^{\prime} \rightarrow 3^{\prime}\right) \\
\text { TTGATTTGGCTGGTAGAA }\end{array}$} \\
\hline$\beta$-actin & Forward & \\
\hline & Reverse & ATGGCAGAAGATTGAGAA \\
\hline \multirow[t]{2}{*}{ GRP78 } & Forward & CGGAGGAGGAGGACAAGAAGGAG \\
\hline & Reverse & ATACGACGGTGTGATGCGGTTG \\
\hline \multirow[t]{2}{*}{$\mathrm{CHOP}$} & Forward & ССTCGCTCTCCAGATTCCAGTCAG \\
\hline & Reverse & TCTCСTGСTССTTCTCCTTCATGC \\
\hline \multirow[t]{2}{*}{ Bax } & Forward & CCAGGACGCATCCACCAAGAAG \\
\hline & Reverse & GCTGCCACACGGAAGAAGACC \\
\hline \multirow[t]{2}{*}{$\mathrm{Bcl}-2$} & Forward & ACGGTGGTGGAGGAACTCTTCAG \\
\hline & Reverse & GTGCAGATGCCGGTTCAGGTAC \\
\hline \multirow[t]{2}{*}{ procaspase- 12} & Forward & AGGGAATCCAGAGCACAGAA \\
\hline & Reverse & GССТTССТTСТССАТСАСТG \\
\hline \multirow[t]{2}{*}{ procaspase-9 } & Forward & CCAGGCAGCTGGTCATAGAT \\
\hline & Reverse & CCACTGCTTTGCAAGAATGA \\
\hline \multirow[t]{2}{*}{ procaspase-3 } & Forward & ACAGAGCTGGACTGCGGTAT \\
\hline & Reverse & TAGTAACCGGGTGCGGTAGA \\
\hline
\end{tabular}

\section{Western blot analysis}

Total protein was extracted from the cell, quantified by BCA kit (Beyotime, China), separated by $10 \%-12 \%$ SDS-PAGE electrophoresis, transferred, sealed, and incubated with different primary antibodies overnight at $4^{\circ} \mathrm{C}$ on NC membranes. Then, the second antibody IgG (1:20,000; ZSGB-BIO, Beijing, China) combine with the primary antibody. Protein expressions were detected by ECL chemiluminescence and exposure by a gel imaging device (ProteinSimple, CA, USA).

\section{Statistical analysis}

The experiment data were expressed as the means \pm standard deviation (S.D.) $(x \pm s)$ and analyzed statistically using SPSS 24.0 software (SPSS, Chicago, IL, USA). The differences in the different groups were detected by the one-way ANOVA analysis, which is considered statistically significant when $P$ value 0.05 .

\section{Results}




\section{Qualitative analysis of HDAX}

Puerarin, acteoside, coptisine, palmatine hydrochloride, berberine, notoginsenoside R1, and ginsenoside Rg1 in HDAX were measured by UPLC, respectively (Figure 1 and Figure 2).

\section{Glucose concentration screening}

PC12 cells were cultured in different densities of glucose $(50,75,100,125,150 \mathrm{mM})$ for 24,48 , and $72 \mathrm{~h}$, the mannitol balances osmotic pressure between different groups. As shown in Figure 3 , Compared with the Control group, when the concentration of building for $100 \mathrm{mM}$ and $125 \mathrm{mM}, 48 \mathrm{~h}$, the cells survival rate is close to $50 \%$. But when the mannitol concentration was $125 \mathrm{mM}$, the cell survival rate was affected $(P<0.05)$. Therefore, according to the MTT results and combined with relevant references, the glucose concentration of $100 \mathrm{mM}$ for $48 \mathrm{~h}$ was selected as the suitable experimental condition for the establishment of the DCD cell model in PC12 cells for the subsequent experiment.

\section{Effects of glucose on cell morphology}

As shown in Figure 4, After $48 \mathrm{~h}$ of culture with different concentrations of glucose, cells in the Control group showed regular morphology, fusiform or polygon, interwoven into a network, adherent to the wall, and good refractive index. With the increase of glucose concentration, the high-glucose injury group was significantly damaged in cell morphology, with different degrees of shrinkage, even shedding, and the intercellular space was increased.

\section{Effects of glucose on cell apoptosis}

To further determine whether high glucose-induced PC12 cell injury and promoted apoptosis, Hoechst 33342 fluorescence staining was used to evaluate the apoptosis of PC12 cells. As shown in Figure 5, after cultured for $48 \mathrm{~h}$ with diverse concentrations of glucose, the cells in Control group showed diffuse and uniform low-density fluorescence. With the increase of glucose concentration, some of the cells in the high-glucose injury group showed high-density fluorescence, and the nucleus appeared to be condensed and fragmented.

\section{HDAX concentration screening}

The experiment was divided into seven groups: Control group, different concentrations of HDAX containing serum groups $(5 \%, 10 \%, 15 \%, 20 \%, 25 \%, 30 \%)$, each group respectively incubated 24 hours. As shown in Figure 6, compared with Control group, cell viability had no significant difference when the concentration of HDAX containing serum was $5 \%-15 \%(P>0.05)$, When the concentration of HDAX containing serum was $20 \%$, the cell viability began to decline; when the concentration was $30 \%$, the cell viability decreased significantly $(P<0.05)$, so $5 \%, 10 \%$, and $15 \%$ dose groups of HDAX containing serum were selected for the next experiment. After treated with high glucose, the cell viability of the $5 \%, 10 \%$ and $15 \%$ dose groups of HDAX containing serum was significantly higher $(P<0.05, P<0.01)$, among which the $15 \%$ dose group of HDAX containing serum had the best effect. 


\section{Effects of HDAX on relevant mRNA levels in apoptosis pathway of ER stress on DCD cell model}

To further explore the effect of the apoptosis pathway of ER stress, we used 4-PBA, an ER stress inhibitor, separately or cotreat with HDAX. Compared with Control group, the mRNA levels in Model group were significantly increased $(P<0.01)$, and $\mathrm{Bcl}-2$ was significantly decreased $(P<0.01)$. After treatment, the mRNA levels in the HDAX group, 4-PBA group, and HDAX+4-PBA group were significantly decreased $(P<0.01)$, and $\mathrm{Bcl}-2$ was significantly increased $(P<0.01)$, compared with Model group.

\section{Effects of HDAX on relevant protein expression in apoptosis pathway of ER stress in DCD in cell model}

After separating or cotreating with 4-PBA, compared with Control group, protein expression was significantly increased $(P<0.01)$ and $\mathrm{Bcl}-2$ protein was significantly decreased in Model group $(P<0.01)$. After treatment, compared with Model group, protein expressions were significantly decreased in HDAX group, 4-PBA group, and HDAX+4-PBA group $(P<0.05, P<0.01)$, the expression of $\mathrm{Bcl}-2$ was significantly increased $(P<0.05, P<0.01)$.

\section{Discussion}

Diabetic cognitive dysfunction (DCD) is a severe diabetes-related complication in the central nervous system [16]. Recent studies have shown that high glucose aggravates neurochemical and structural abnormalities in the brain, which is the most fundamental cause of DCD. Even in non-diabetic patients, impaired glucose tolerance is also an important risk factor for cognitive dysfunction [17]. High glucose can induce neuronal apoptosis and cognitive dysfunction by activating microglial inflammatory response, contributing to the occurrence and development of diabetic encephalopathy and neurodegenerative diseases [18]. It can also change the permeability of blood-brain barrier, thus accelerating the occurrence of cognitive impairment in diabetic patients [1]. As the pathological basis of DCD, it is the research direction of this experiment. In addition, previous studies have shown that HDAX is effective in the treatment of the rat model of DCD [19]. In this experiment, we further study the neuroprotective mechanism of HDAX in the DCD cell model.

First, we took PC12 cells as the main research object, which simulated high glucose and induced neurotoxicity. MTT assay, inverted microscope, and Hoechst 33342 fluorescence staining showed that cell viability significantly reduced with $100 \mathrm{mM}$ high glucose treatment for $48 \mathrm{~h}$, changed cell morphology, and promoted cell apoptosis. These results indicated that high glucose $100 \mathrm{mM}$ induction for $48 \mathrm{~h}$ was the suitable experimental condition for PC12 cells to establish a high glucose injury model in vitro, which was consistent with the research results of other scholars $[20,21]$. 
Then, we explored the therapeutic effect of HDAX in DCD. HDAX is rooted in the classical prescription "Xiao-Ke Formula", which is mainly composed of Coptidis Rhizoma, Radix Rehmanniae, Radix Puerariae, Radix Ophiopogonis, Eriobotryae Folium, and Radix Notoginseng. It has been used in the treatment of diabetes and its complications for several years, but it has rarely been studied in the research on DCD. We reanalyzed the HDAX pharmacological formula from the perspective of modern pharmacological research. In this prescription, Berberine, the main component of Coptidis Rhizoma, can ameliorate rats model of combined Alzheimer's disease and type 2 diabetes mellitus via the suppression of ER stress [22]. Studies in Radix Ophiopogonis showed that it reducing cell apoptosis, protecting islets, and improving insulin resistance [23]. Panax notoginseng saponins are the major active ingredients of Radix Notoginseng, which can keep neurons from oxidative stress damage, ameliorate learning and memory deficits in AD rats [24]. Therefore, we proposed a hypothesis that HDAX can improve DCD. We studied the neuroprotective effect of HDAX on DCD for the first time in vitro. In this experiment, we proved that HDAX can improve the cell vitality of the DCD cell model and exert its neuroprotective effect.

Next, we further explored whether the mechanism of HDAX protecting neurons is related to the inhibition of the apoptosis pathway of ER stress. We selected the related proteins and genes in this pathway for comparison, and the results were consistent with our expectations. Glucose regulated protein 78 (GRP78) was a symbolic protein and protective factor of ER stress and had the function of protecting the endoplasmic reticulum under stress [25]. CHOP was extensively induced and expressed under ER stress, and finally induces apoptosis through the mitochondrial pathway [26]. Bcl-2-associated X protein (Bax) was a pro-apoptotic protein that promoted the occurrence of apoptosis, and Bcl-2 was an anti-apoptotic protein, inhibited the occurrence of apoptosis. They usually existed in the form of heterodimers and jointly regulated the process of cell apoptosis [27]. Caspases were the core component of the apoptosis reaction. Caspase-12 was a specific apoptosis mediator in ER stress-mediated apoptosis pathway. Under normal circumstances, Caspase-12 bonded to ER membrane or formed a hetero with tumor necrosis factor receptor-associated factor 2 inactive. However, in the case of the excessive ER stress response, Caspase-12 activates downstream molecules Caspase-9 and Caspase-3 [28]. Caspase-3 was an important protease for the executive function of apoptosis. It was located downstream of the Caspase cascade and was considered to be the endpoint of apoptosis [29]. In this experiment, Our findings showed that HDAX can improve the relevant protein expression and mRNA levels after treatment. Moreover, treatment with 4-phenylbutyric acid (4-PBA), as well as cotreatment with HDAX and 4-PBA, significant inhibition of cell damage, which further demonstrated that the potential mechanism of HDAX to improve DCD by restraining the apoptosis pathway of ER stress.

\section{Conclusions}

Our findings suggest that HDAX was confirmed with a protective effect on DCD models, which might be associated with the inhibition of the apoptosis pathway of ER stress. However, there still needs deeper exploration. These data may help to explain the potential neuroprotective mechanism of HDAX on DCD. 


\section{Abbreviations}

HDAX: Huangdi Anxiao; DCD: Diabetic cognitive dysfunction; ER: endoplasmic reticulum; AD: Alzheimer's disease; T2DM: Type 2 diabetes mellitus; AB: Amyloid beta-peptide; UPR: Unfolded protein response; PBS: Phosphate-buffered saline; Caspase: Cysteinyl aspartate specific proteinase; Bcl-2: B-cell lymphoma-2; CHOP: C/EBP homologous protein; Bax: Bcl-2-associated $\mathrm{X}$ protein

\section{Declarations}

\section{Acknowledgments}

This study was supported by the National Natural Science Foundation of China (81574040 and 81873351) and the Key Project Foundation of Support Program for the Excellent Young Faculties in Universities of Anhui Province in China (grant no. gxyq ZD2018053).

\section{Authors' Contributions}

BC, GW, ZF and TY designed the study. TY, WX, PZ, NS, YW, TW, and HS performed the experiments. TY, WX and GH wrote the manuscript. All authors approved the paper to be published.

\section{Availability of data and materials}

The data will be made available upon reasonable request.

\section{Ethics approval and consent to participate}

The study protocol was approved by the Animal Manage[1]ment Center of the Anhui University of Chinese Medicine,China.

\section{Consent for publication}

All authors agree to publish the manuscript.

\section{Competing interests}

The authors declare that they have no competing interests.

\section{References}

1. Liu Y, Yu J, Shi YC, Zhang Y, Lin S. The role of inflammation and endoplasmic reticulum stress in obesity-related cognitive impairment. Life sciences. 2019;233: 116707.

2. Callisaya ML, Beare R, Moran C, Phan T, Wang W, Srikanth VK. Type 2 diabetes mellitus, brain atrophy and cognitive decline in older people: a longitudinal study. Diabetologia. 2019;62(3):448-458. 
3. Cassano V, Leo A, Tallarico M, Nesci V, Cimellaro A, Fiorentino TV, Citraro R, Hribal ML, De Sarro G, Perticone F, Sesti G, Russo E, Sciacqua A. Metabolic and cognitive effects of ranolazine in type 2 diabetes mellitus: data from an in vivo model. Nutrients. 2020;12(2), 382.

4. Xu YX. Based on JNK/MLCK pathways to explore the role of green tea in diabetic encephalopathy hippocampal nerve cells apoptosis mechanism. Guizhou Medical University. 2019.

5. Huang HJ, Chen SL, Huang HY, Sun YC, Lee GC, Lee-Chen GJ, Hsieh-Li HM, Su M T. Chronic low dose of AM404 ameliorates the cognitive impairment and pathological features in hyperglycemic 3xTg-AD mice. Psychopharmacology. 2019; 236(2):763-773.

6. Lee HJ, Yang SJ. Supplementation with Nicotinamide Riboside reduces brain inflammation and improves cognitive function in diabetic mice. International journal of molecular sciences. 2019; 20(17):4196.

7. You S, Kim GH. Protective effect of Mori Cortex radicis extract against high glucose-induced oxidative stress in PC12 cells. Bioscience, biotechnology, and biochemistry. 2019; 83(10): 1893-1900.

8. Saberi Firouzi S, Namazi Sarvestani N, Bakhtiarian A, Ghazi Khansari M, Karimi MY, Ranjbar A, Safa M, Hosseini A. Sildenafil protective effects on high glucose-induced neurotoxicity in PC12 cells: the role of oxidative stress, apoptosis, and inflammation pathways in an in vitro cellular model for diabetic neuropathy. Neurological research. 2018; 40(8): 624-636.

9. Wu P, Shi X, Luo M, Inam-U-Llah, Li K, Zhang M, Ma J, Li Y, Liu Y, Zhang C, Liu X, Li S, Li Q, Chen X, Che $X, \&$ Piao F. Taurine inhibits neuron apoptosis in hippocampus of diabetic rats and high glucose exposed HT-22 cells via the NGF-Akt/Bad pathway. Amino acids. 2020; 52(1): 87-102.

10. Zhang YW, Wang X, Ren X, \& Zhang M. Involvement of glucose-regulated protein 78 and spliced Xbox binding protein 1 in the protective effect of gliclazide in diabetic nephropathy. Diabetes research and clinical practice. 2018; 146: 41-47.

11. Li W, Li W, Leng Y, Xiong Y, \& Xia Z. Ferroptosis Is involved in diabetes myocardial ischemia/reperfusion injury through endoplasmic reticulum stress. DNA and cell biology. 2020; 39(2): 210-225.

12. Iurlaro R, Muñoz-Pinedo C. Cell death induced by endoplasmic reticulum stress. The FEBS journal. 2016; 283(14): 2640-2652.

13. Guo MF, Gao JR, , Wang JQ, Jiang H, Fang ZH, Wei LB. Effects of Huangdi Anxiao capsule on insulin tolerance and IRS-1 protein expression in GK rats. Journal of Jiangxi University of Traditional Chinese Medicine. 2020; 32(06): 91-94.

14. Gao JR, Guo MF, Jiang H, Fang ZH, Xu YQ, Wei LB, Shan L. Protective effects of Huangdi Anxiao capsule on zebrafish vascular lesions induced by high-glucose and high-fat. Journal of Liaoning University of Traditional Chinese Medicine. 2019; 21(04): 24-27.

15. Cai B, Ye S, Wang Y, Wang TT, Wang L, Jiang AJ, Shen GM, Xie DJ. Effects of Huangpu Tongqiao capsule on apoptosis of Alzheimer's disease cell model. China Journal of Chinese Materia Medica. 2018; 43(11): 2378-2383. 
16. Wang C, Li J, Zhao S, \& Huang L. Diabetic encephalopathy causes the imbalance of neural activities between hippocampal glutamatergic neurons and GABAergic neurons in mice. Brain Res. 2020; 1742:146863.

17. Sharma G, Parihar A, Talaiya T, Dubey K, Porwal B, \& Parihar MS. Cognitive impairments in type 2 diabetes, risk factors and preventive strategies. Journal of Basic and Clinical Physiology and Pharmacology. 2020;31(2):141-68.

18. Yang L, Tong Y, Chen PF, Miao S, Zhou RY. Neuroprotection of dihydrotestosterone via suppression of the toll-like receptor 4/nuclear factor-kappa B signaling pathway in high glucose-induced BV-2 microglia inflammatory responses. Neuroreport. 2020; 31(2): 139-147.

19. Xuan WT, Cai B, Ye T, Gao HW, Fang ZH, Ye S, Wang Y, Wang H. Neuroprotective effect of Huangdi Anxiao capsule in rats with diabetic cognitive dysfunction and related mechanisms. J Anhui Univ chinese med. 2020; 39(02):63-68.

20. Wang K, Fu XY, Fu XT, Hou YJ, Fang J, Zhang S, Yang MF, Li DW, Mao LL, Sun JY, Yuan H, Yang XY, Fan CD, Zhang ZY, \& Sun BL. DSePA antagonizes high glucose-induced neurotoxicity: evidences for DNA damage-mediated p53 phosphorylation and MAPKs and AKT pathways. Molecular neurobiology. 2016; 53(7): 4363-4374.

21. Wang M, Yan W, Liu Y, Hu H, Sun Q, Chen X, Zang W, Chen L. Erythropoietin ameliorates diabetesassociated cognitive dysfunction in vitro and in vivo. Scientific reports. 2017; 7(1): 2801.

22. Xuan WT, Wang H, Zhou P, Ye T, Gao HW, Ye S, Wang JH, Chen ML, Song H, Wang Y, \&Cai B. Berberine ameliorates rats model of combined Alzheimer's disease and type 2 diabetes mellitus via the suppression of endoplasmic reticulum stress 3 Biotech. 2020; 10(8), 359.

23. Wang L, Qin JG, Wang C. Effect of Ophiopogonis Radix extract on expression of miRNA-29a and FoxO3 in liver tissue of insulin resistant rats. Chinese Journal of Experimental Traditional Medical Formulae.2018; 24(01):124-129.

24. Zhou L, Huang PP, Chen LL, Wang P. Panax Notoginseng Saponins ameliorate A $\beta$-mediated neurotoxicity in $\mathrm{C}$. elegans through antioxidant activities. Evidence-based complementary and alternative medicine: eCAM. 2019; 2019:7621043.

25. Tang L, Ren X, Han Y, Chen L, Meng X, Zhang C, Chu H, Kong L, Ma H. Sulforaphane attenuates apoptosis of hippocampal neurons induced by high glucose via regulating endoplasmic reticulum. Neurochemistry international. 2020; 136:104728.

26. Pan X, Zhu Y, Wu X, Liu L, Ying R, Wang L, Du N, Zhang J, Jin J, Meng X, Dai F, Huang. The interaction of ASIC1a and ERS mediates nerve cell apoptosis induced by insulin deficiency. European journal of pharmacology. 2021; 893:173816.

27. Campbell KJ. Targeting BCL-2 regulated apoptosis in cancer. Open biology. 2018; 8(5): 180002.

28. Yang J, Zhu D, Wen L, Xiang X, Hu J. Gentianella turkestanerum Showed Protective Effects on Hepatic Injury by Modulating the Endoplasmic Reticulum Stress and NF-KB Signaling Pathway. Current molecular medicine. 2019; 19(6): 452-460. 
29. Ma Y, Xiong L. Astragaloside IV ameliorates endoplasmic reticulum stress-induced apoptosis of A 25 -35-treated PC12 cells by inhibiting the p38 MAPK signaling pathway. Molecular medicine reports. 2019; 19(3):2005-2012.

\section{Figures}
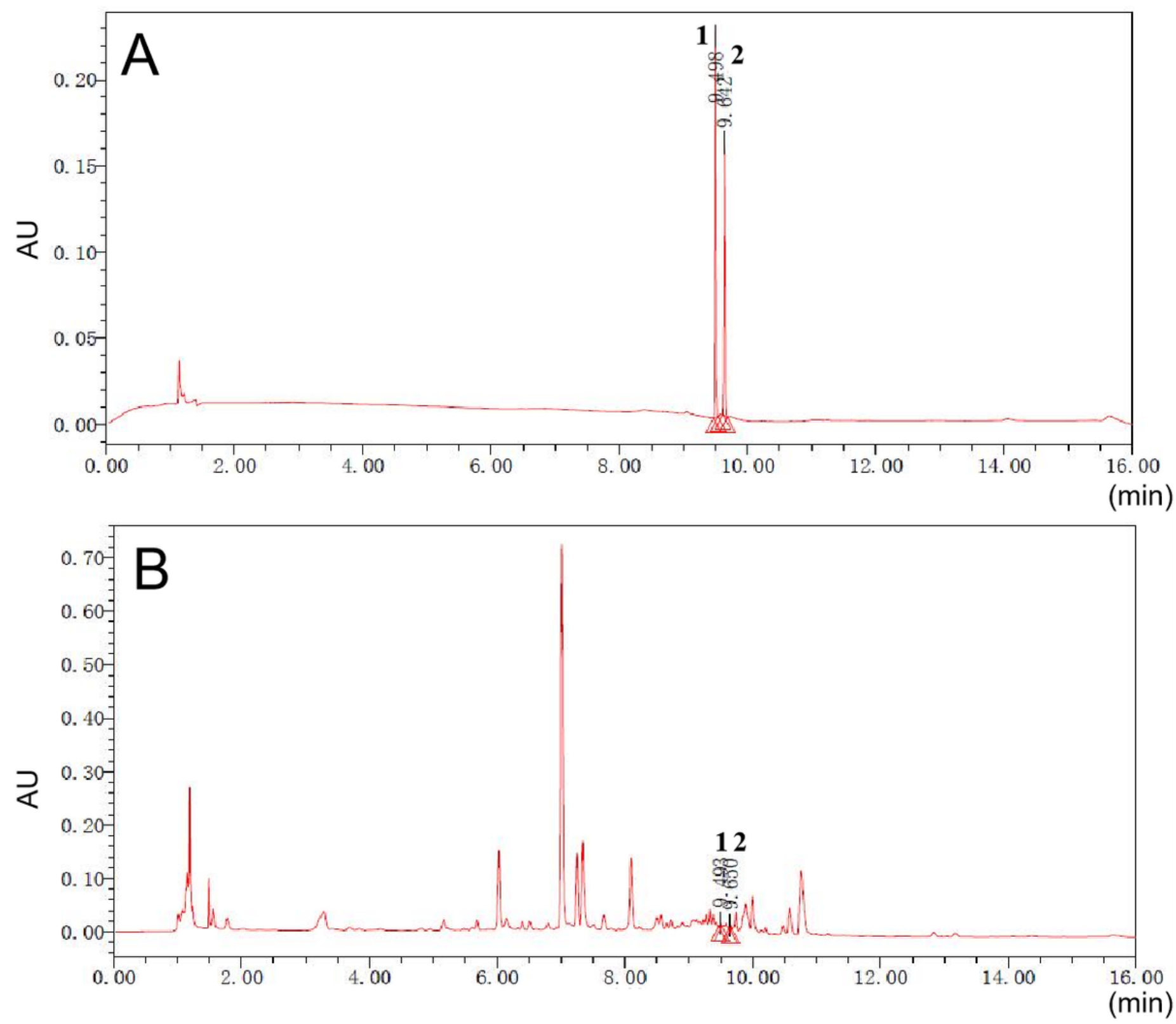

Figure 1

Peak chromatograms of HDAX at $203 \mathrm{~nm}$. (A) Mixed standard chromatogram (1. Notoginsenoside R1, 2. Ginsenoside Rg1), (B) HDAX chromatogram. 

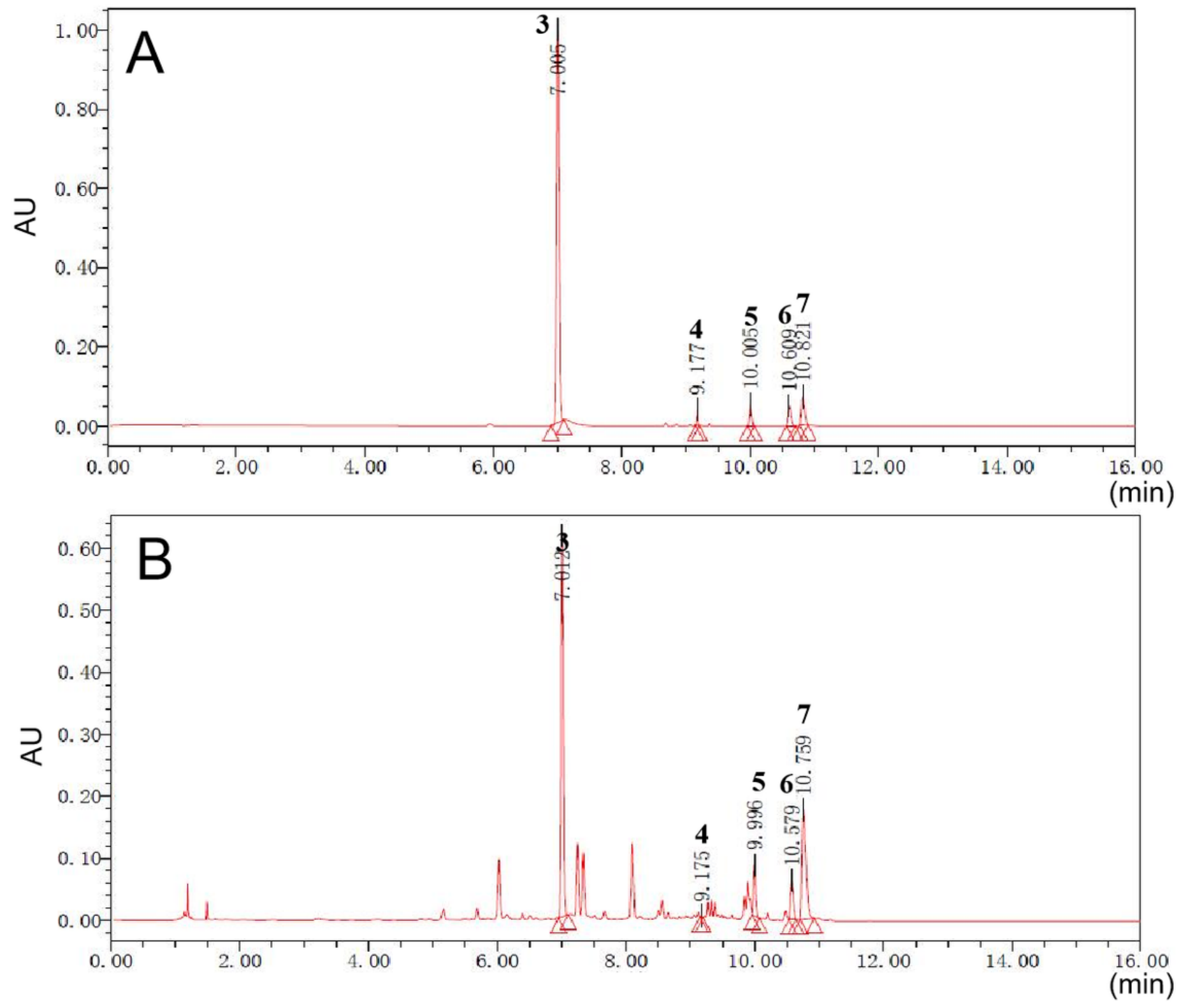

Figure 2

Peak chromatograms of HDAX at $260 \mathrm{~nm}$. (A) Mixed standard chromatogram (3. Puerarin, 4. Acteoside, 5. Coptisine, 6. Palmatine hydrochloride, 7. Berberine). (B) HDAX chromatogram. 

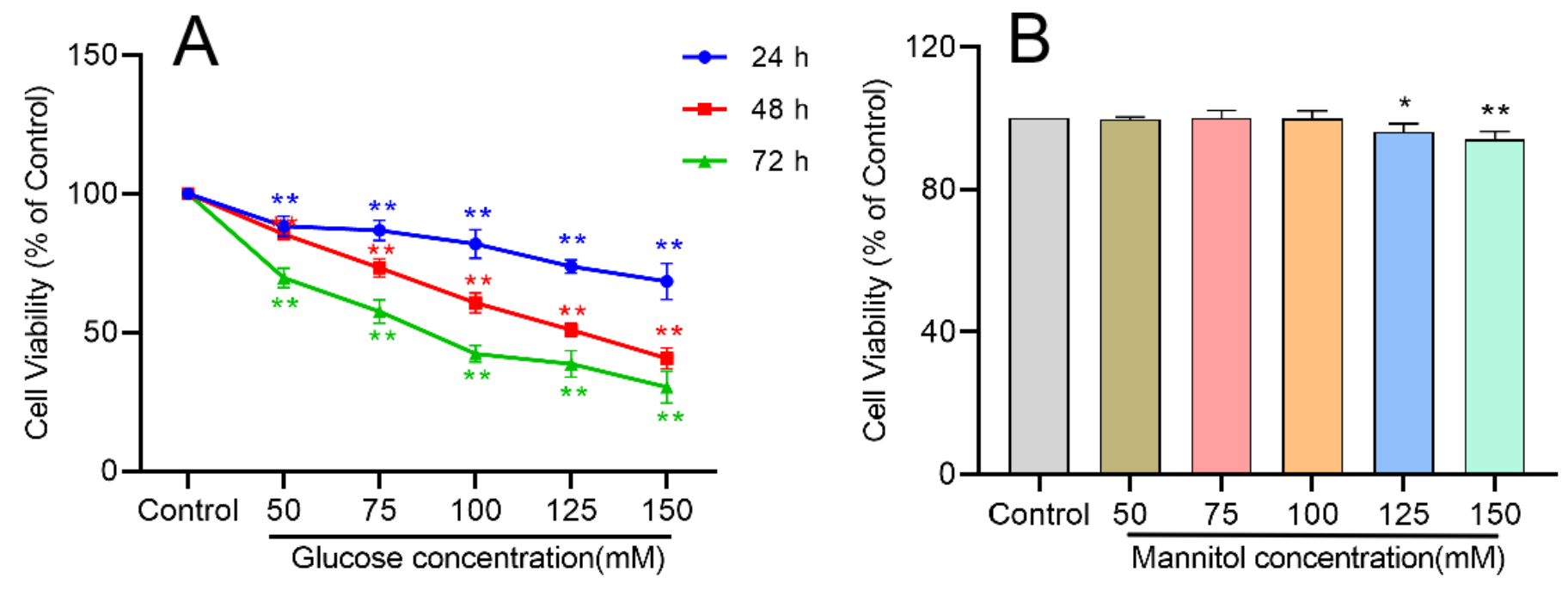

\section{Figure 3}

Effects of different times and concentrations of glucose on cell viability. (A) PC12 cells viability in $24 \mathrm{~h}$, $48 \mathrm{~h}$, and $72 \mathrm{~h}$. (B) PC12 cells viability in different mannitol concentrations. The values are presented as the means \pm S.D. of 3 individual experiments. Compared to the Control, ${ }^{\star} P<0.05,{ }^{\star \star} P<0.01$.
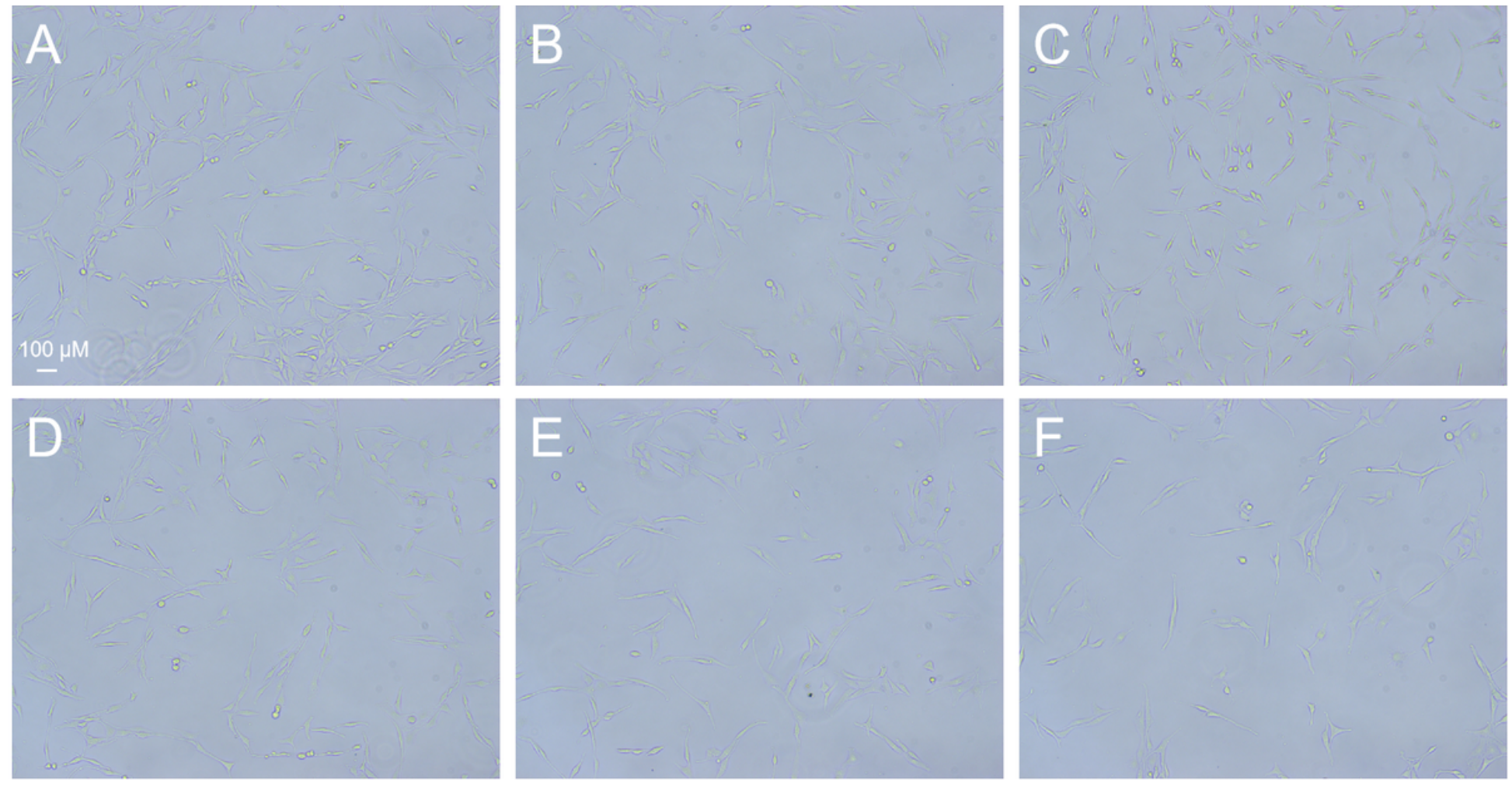

Figure 4

Morphological effects of different glucose concentrations on PC12 cells (100x). (A) Control; (B) $50 \mathrm{mM}$ glucose (C) 75 mM glucose; (D) 100 mM glucose; (E) 125 mM glucose; (F) 150 mM glucose. 

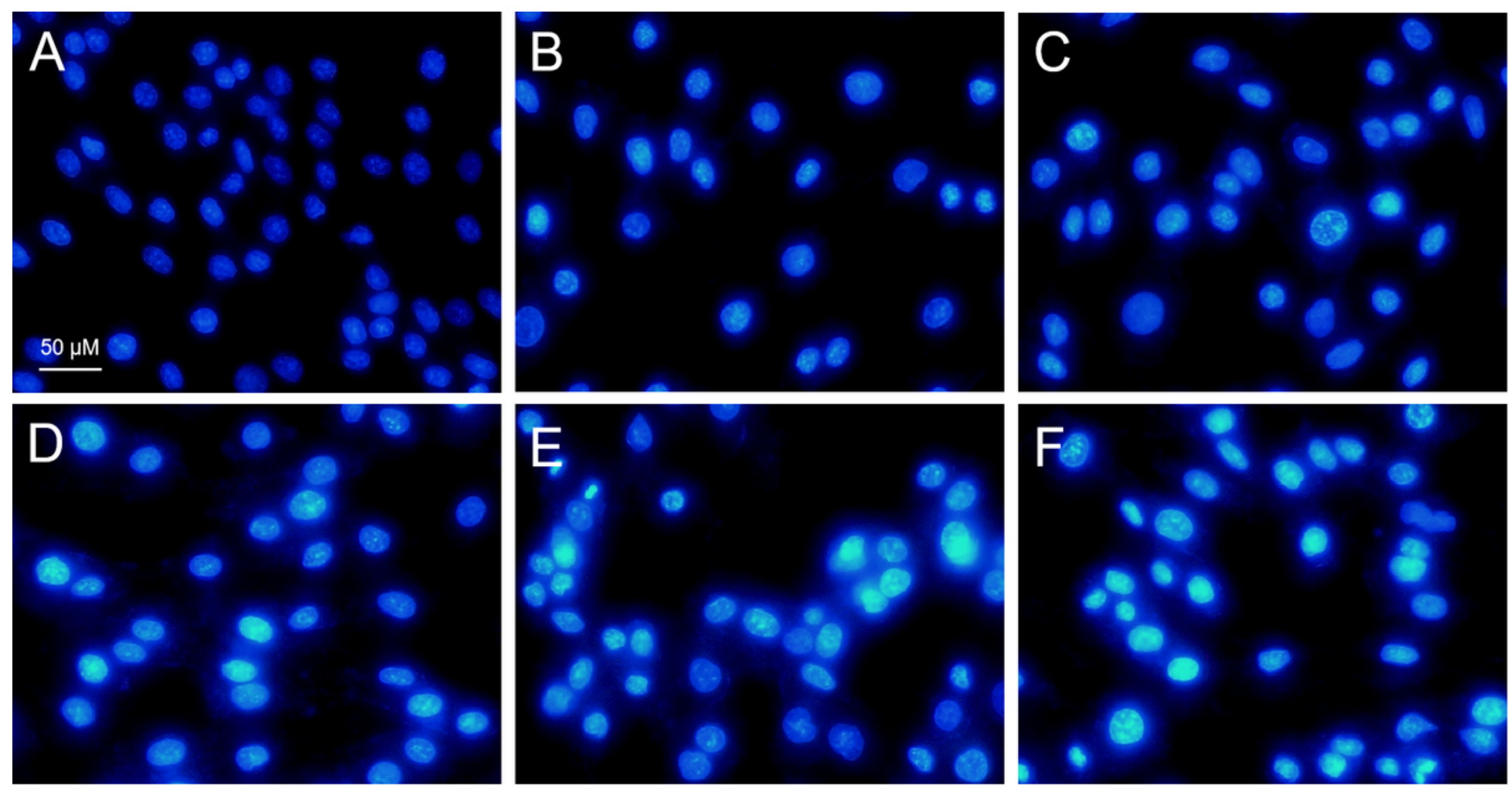

\section{Figure 5}

Apoptosis of PC12 cells was observed under fluorescence microscope (200x). (A) Control; (B) $50 \mathrm{mM}$ glucose; (C) 75 mM glucose; (D) 100 mM glucose (E) 125 mM glucose; (F) 150 mM glucose.
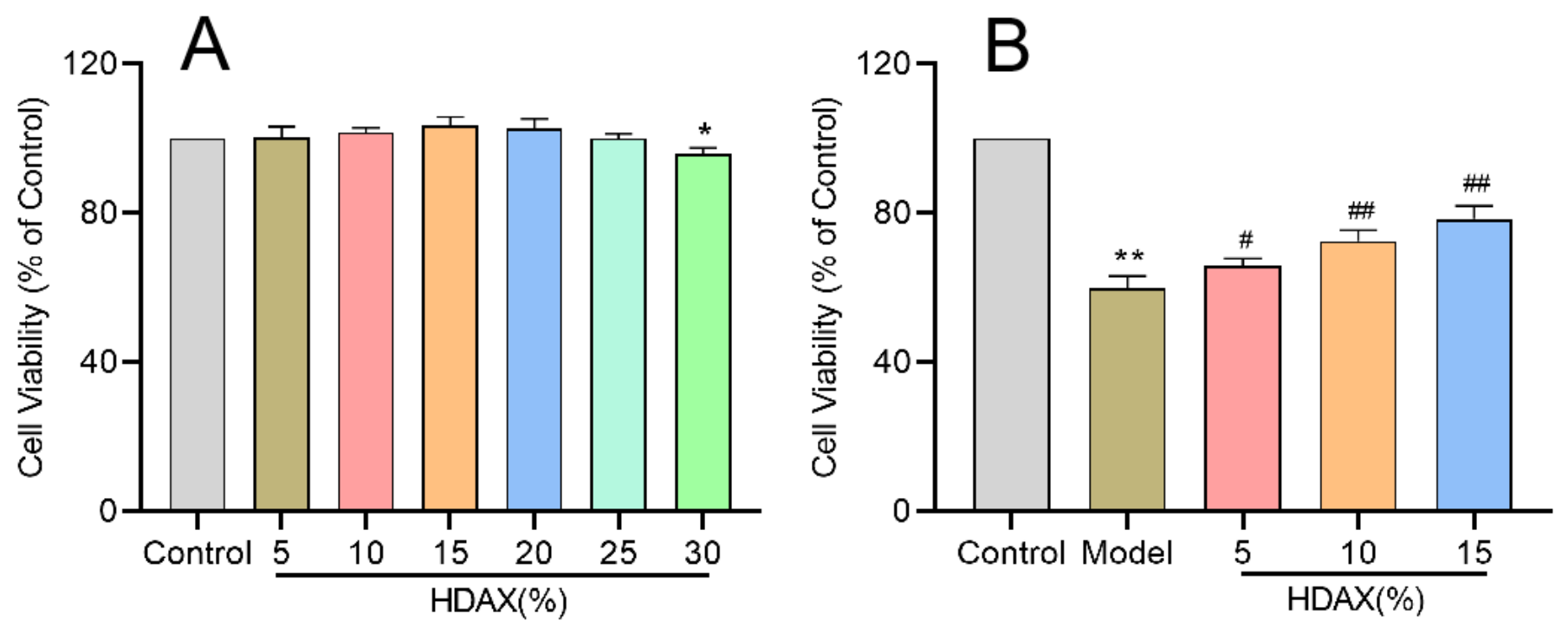

Figure 6

HDAX concentration screening. (A) Effects of different concentrations of HDAX containing serum on the survival rate of PC12 cells. (B) Effect of different concentrations of HDAX containing serum on the 
survival rate of cell model. The values are presented as the means \pm S.D. of 3 individual experiments. Compared to the Control, ${ }^{* *} P<0.01$; compared to the Model, ${ }^{\#} P<0.05,{ }^{\# \#} P<0.01$.

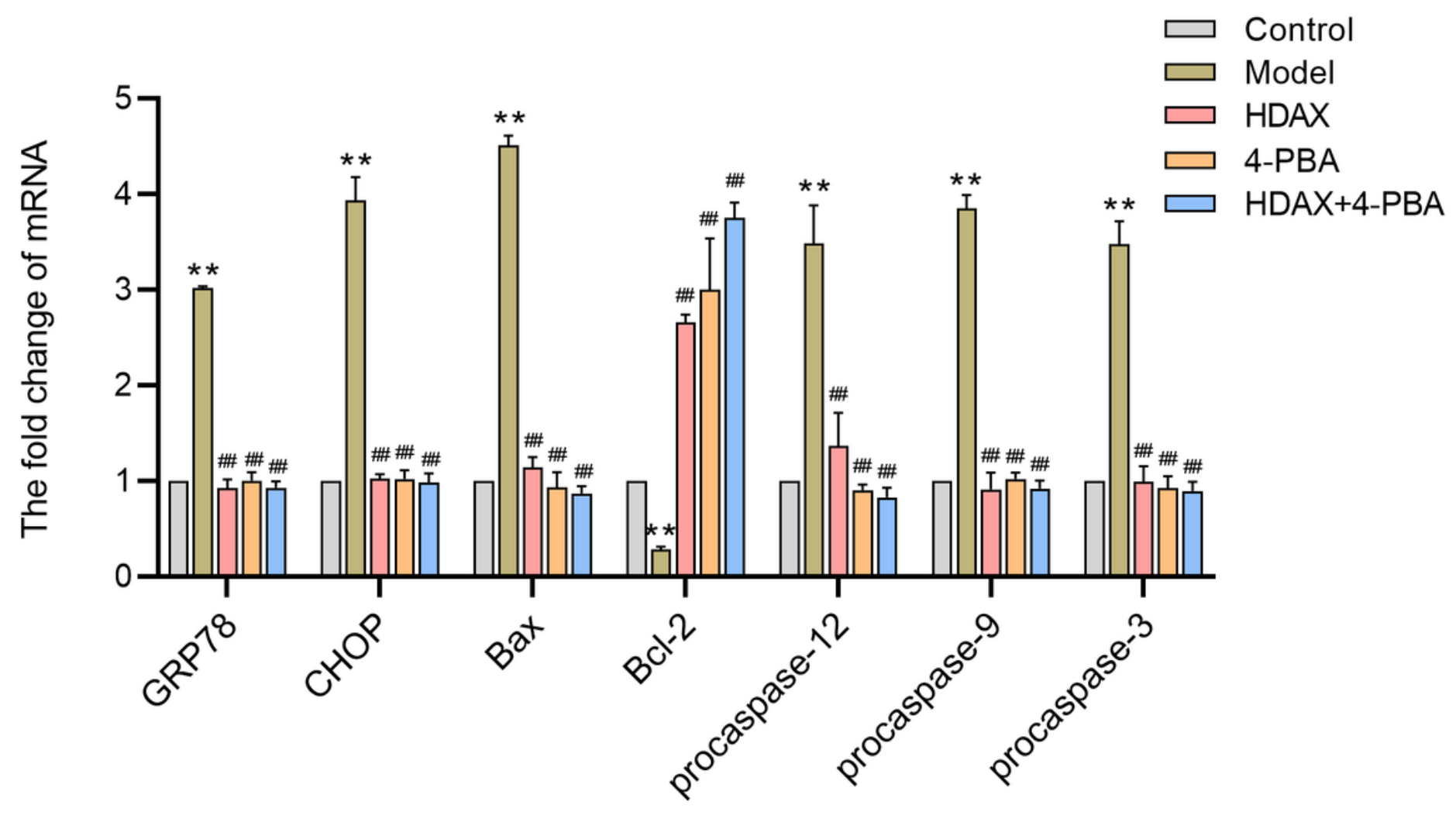

Figure 7

Effect of HDAX on mRNA levels of GRP78, CHOP, Bax, Bcl-2, procaspase-12, procaspase-9, and procaspase 3 in DCD cell model. The values are presented as the means \pm S.D. of 3 individual experiments. Compared to the Control, ${ }^{*} P<0.05,{ }^{* *} P<0.01$; compared to the Model, ${ }^{\#} P<0.05,{ }^{\# \#} P<0.01$. 

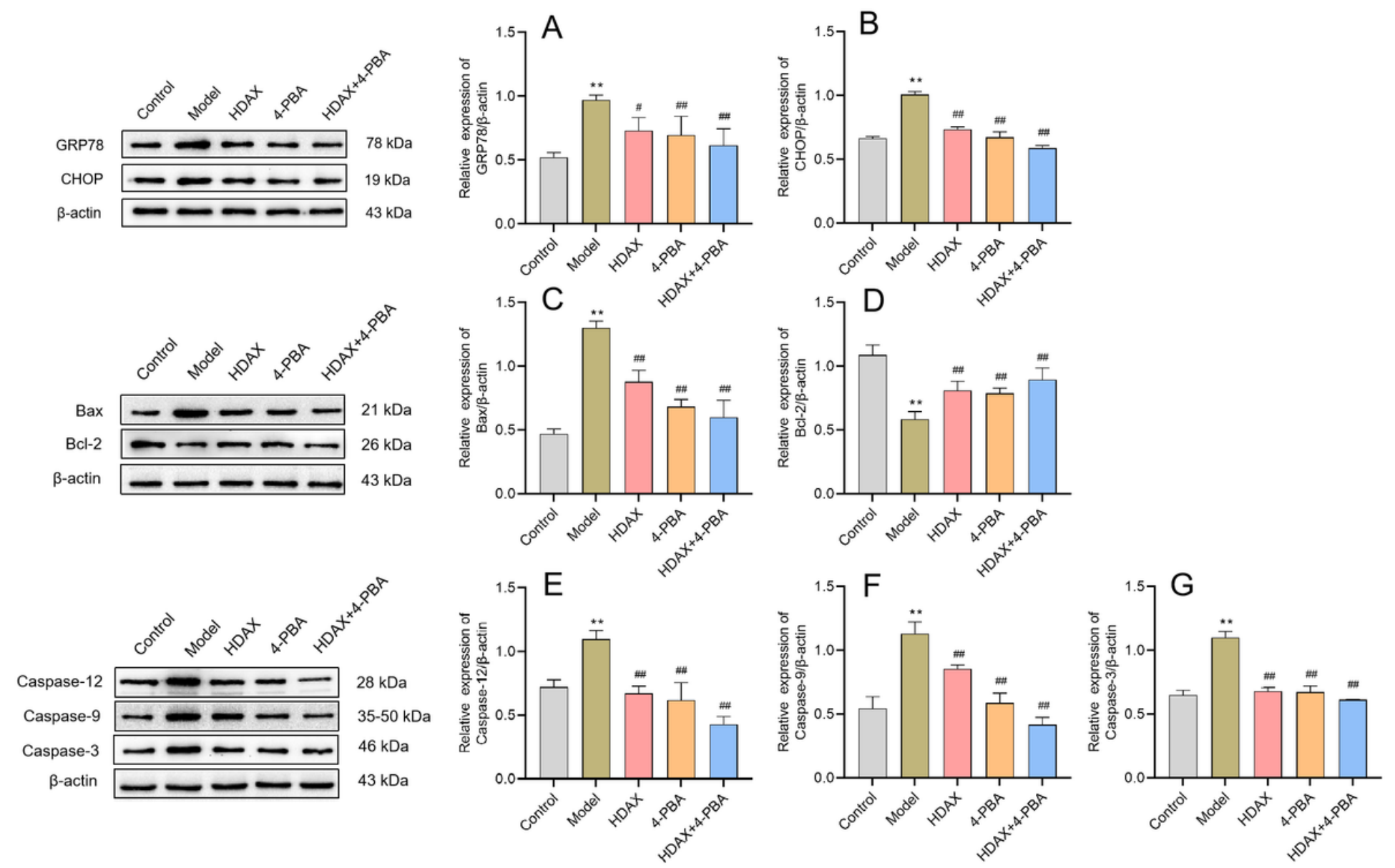

Figure 8

Effect of HDAX on the protein expression of GRP78, CHOP, Bax, Bcl-2, Caspase-12, Caspase-9, and Caspase-3 in DCD cell model (A-G). The values are presented as the means \pm S.D. of 3 individual experiments. Compared to the Control, ${ }^{*} P<0.05 ;{ }^{* \star} P<0.01$; compared to the Model, ${ }^{\#} P<0.05$; ${ }^{\# \#} P<0.01$. 